\title{
COVID-19 Y EL CIERRE DE ESCUELAS: aportes de las ciencias sociales para la construcción de un currículo postcrítico desde el GEOFORO Iberoamericano
}

\author{
Silvia Aparecida de Sousa Fernandes \\ Universidade Estadual Paulista (UNESP) - Marília \\ Diego García Monteagudo \\ Universidad de Valencia, Espanha \\ Nancy Palacios Mena \\ Universidad de los Andes, Colômbia
}

\begin{abstract}
Resumen
El artículo discute la concepción que el profesorado y alumnado de tres países iberoamericanos (Brasil, Colombia y España) presentan como experiencias y determinaciones escolares frente a la pandemia de la COVID-19, a través del análisis del foro 26 del GEOFORO - Foro Iberoamericano sobre Educación, Geografía y Sociedad. El objetivo que pretendemos conseguir es doble: por un lado, analizar los elementos que influyen en la concepción del virus en cada uno de esos países; y por otro, conocer los discursos del profesorado en activo y en formación en aspectos concernientes al mundo educativo desde el contexto iberoamericano. Partimos de la afirmación de que los desafíos que enfrentan los docentes en educación básica y las demandas de educación remota son mayores en el contexto de la pandemia actual, ya que las situaciones de aislamiento social y cuarentena presentan nuevos desafíos para la implementación de los planes de estudios y el desarrollo de prácticas educativas en torno a las ciencias sociales. Se producen así nuevos discursos educativos, adaptaciones curriculares y prácticas, que deben tenerse en cuenta en la construcción de un currículo sobre la enseñanza de las ciencias sociales en el ámbito iberoamericano para el desarrollo de una ciudadanía crítica.
\end{abstract}

Palabras clave: Política Educacional, Currículo, Estrategias educativas, Actitud del docente, GEOFORO

\begin{abstract}
The article discuss the conception that teachers and students of three iberoamerican countries (Brazil, Colombia and Spain) presents as school experiences and decisions facing the COVID-19 pandemic, by the analysis of the Foro 26 of GEOFORO - Iberoamerican Forum of Education, Geography and Society. It intends to achieve a dual goal: on the one hand, analyze the aspects that influence the conceptions about the pandemic in each country; on the other hand, know the speeches of the in-service and training teachers, in aspects that concerns the educational world since the iberoamerican context. We start from the afirmation that the challenges faced by the professors of basic education and the demands of remote education are bigger in the context of the current pandemic, since the social isolation and quarentine situation introduce new challenges for the implementation of syllabus and the development of educational practices. Therefore, new educational speeches, curricular adaptations and practices that should be considered in the construction of a curriculum to the Social Sciences teaching in the iberoamerican scope are produced, aiming the development of a critical citizenship.
\end{abstract}

Keywords: Educational policy, Curriculum, Educational strategies, Teacher's attitude, GEOFORO

ISSN 1645-1384 (online) www.curriculosemfronteiras.org 


\section{Introducción}

Una de las consecuencias que ha producido la expansión de la pandemia que ha recorrido el mundo desde finales del 2019, es la suspensión de las actividades educativas presenciales en una gran cantidad de países. Según datos de la UNESCO (2020) en 184 países el 89\% de los estudiantes matriculados en algún nivel de escolaridad dejaron de asistir de manera presencial a los establecimientos educativos. En Iberoamérica los cierres habrían afectado a 177 millones de estudiantes (OEI, 2020).

Ante la necesidad de implementar el aislamiento social para frenar la expansión del virus, las autoridades educativas centraron las acciones en garantizar la continuidad de los procesos de aprendizaje por medio de la ejecución de clases virtuales y trabajo en casa. Las prácticas educativas virtuales que se han desarrollado abarcan diversas modalidades que incluyen clases sincrónicas, asincrónicas, el uso de masivo de plataformas y dispositivos electrónicos para garantizar la interacción online de los profesores con sus estudiantes, envío de guías de trabajo para realizar en casa (Chan; Yano, 2020). En este orden de ideas, desde la perspectiva de Pedró (2020, p. 36), "hemos presenciado las más variadas soluciones de educación a distancia para seguir la continuidad pedagógica". En otra vertiente existe el debate sobre la oscuridad de estos estudios y la incertidumbre sobre los aprendizajes de los alumnos en esta nueva realidad.

Uno de los estudios que ha publicado la UNESCO (2020) en el marco de la pandemia indica que la mayor parte de los sistemas educativos han tenido tres prioridades: la conectividad de profesores y docentes a internet, los efectos económicos del cierre de los establecimientos educativos y las dificultades para mantener las dinámicas escolares tanto en materia de enseñanza como de aprendizaje. Si bien las preocupaciones por los efectos de la expansión del virus son comunes a todos los ámbitos de la vida, desde el punto de vista de la UNESCO (2020), las preocupaciones de quienes lideran y orientan los sistemas educativos se focalizan en estudiantes y familias que ya vivían situaciones que los hacían más vulnerables con anterioridad a la aparición del virus. A las precarias condiciones económicas que ya tenían una parte de los estudiantes se le ha sumado el esfuerzo que han tenido que hacer para adaptarse a nuevas modalidades y metodologías de enseñanza y aprendizaje que, en su mayoría, exigen tener tanto dispositivos electrónicos como conexión a internet.

$\mathrm{Si}$ mencionamos solamente las regiones en las que están ubicados los países Iberoamericanos, los datos indican que en Europa el 83\% de los hogares tiene conexión a internet y en América Latina y el Caribe el porcentaje es del 45\%. Lo que ilustran los datos es que hay un porcentaje considerable de familias cuyos hijos no cuentan con condiciones apropiadas de conectividad, situación a la que hay que agregar que "los sistemas educativos tampoco tienen capacidad real de asumir el número de conexiones simultáneas requeridas para dar continuidad pedagógica si realmente la mayoría de los estudiantes lo utilizara de forma intensiva" (UNESCO, 2020, p.20)

Desde la postura de Cotino (2020); Harris (2020); Giannini, Grant (2020) el Coronavirus ha sacado a relucir el panorama de desigualdades que caracteriza el mundo contemporáneo, y abrirá más el profundo abismo de desventadas entre unos sectores sociales y otros en 
materia educativa. El informe de la $\operatorname{UNESCO}(2020$, p. 14) subraya que "la pandemia añade un grado más de complejidad crítica a una educación ya enfrentada a retos no resueltos como un crecimiento sin garantías de calidad, inequidades en el acceso, en los logros y en la pérdida del financiamiento público".

En consecuencia, como señala Cotino (2020) los hijos de las familias más pobres aprenderán menos, puesto que los ingresos y otras circunstancias muy vinculadas a la situación económica van a repercutir en la capacidad de lograr los objetivos de la educación a través de internet y bajo las circunstancias que obliga la pandemia. En coincidencia con los planteamientos anteriores, Palacios (2020) resalta que la literatura nos indica que las brechas educativas no son nuevas, sencillamente se han hecho mucho más evidentes con la pandemia y se profundizarán con ella. Si bien es cierto se han implementado acciones nacionales, locales y a nivel de las instituciones educativas, con recursos económicos e imaginación pedagógica para que los niños y jóvenes sigan aprendiendo, es claro que en vastas zonas de la región estas iniciativas son insuficientes.

Para que podamos comprender las transformaciones recientes en el mundo de la educación, impuestas por una nueva realidad social, sanitaria y económica en medio del avance de la pandemia, debemos utilizar diferentes prismas o perspectivas de análisis: por un lado, los determinantes globales, como la propagación de la enfermedad en todo el mundo, y las respuestas globales de la UNESCO a la educación; por otro, las políticas locales impulsadas por los gobiernos nacionales y regionales, las decisiones institucionales que dependen de cómo las escuelas reciben y llevan a cabo dichas políticas, y las respuestas de los sujetos sociales en su ámbito más próximo de actuación (escuelas, institutos, universidades).

Una gran cantidad de artículos en la prensa se han referido a esta multiplicidad de temas y decisiones políticas en todo el mundo e intentan comprender esta nueva realidad. Algunos anuncios en la televisión hablan de una nueva normalidad y ruegan para que los avances en la ciencia nos traigan de vuelta las certezas cotidianas que la pandemia nos ha quitado. Por todo ello nos ha interesado conocer las opiniones y preocupaciones de docentes en activo y en formación, acerca de la pandemia y sus efectos en distintos ámbitos que trascienden la esfera de la educación. Esto ha sido posible por el trabajo que una comunidad de profesorado iberoamericano (Brasil, Chile, Colombia, España, Portugal, Argentina, México, Perú y Venezuela) vienen desarrollando en el GEOFORO Iberoamericano sobre Sociedad, Geografía y Educación desde 2009. Se trata de una plataforma digital que pretende difundir y compartir ideas, debates, experiencias y resultados científicos sobre la educación geográfica en el contexto iberoamericano con una media de visitas de 20.000 personas al año (Fita; Loureiro; Souto, 2018). En su primera década de funcionamiento se han abierto 25 foros específicos con temáticas acerca de la educación ambiental, los libros de texto y la enseñanza de la geografía, las unidades didácticas, la formación del profesorado y las salidas de campo, por mencionar sólo aquellos que cuentan con más participación (Rodrígues; Palacios; Souto, 2019).

En este contexto de participación activa del profesorado el comité directivo de dicho GEOFORO ha creado el foro 26 titulado "El coronavirus, una experiencia de aprendizaje" 
para debatir acerca del COVID-19 y sus implicaciones en diversas esferas y espacios iberoamericanos. En concreto, el 20 de marzo de 2020 se abrió este espacio con la intención de reflexionar sobre la situación mundial de la pandemia y analizar cómo afectan las decisiones políticas, económicas y sanitarias al comportamiento de las personas, y cómo ello se refleja en el territorio y en la educación. De esta manera se han registrado 165 comentarios hasta finales de julio de 2020, de los que tan solo analizaremos con mayor profundidad los correspondientes a los participantes de Brasil, Colombia, y España desde el 20 de marzo al 30 de junio de 2020. El objetivo que pretendemos conseguir es doble: por un lado, analizar los elementos que influyen en la concepción del virus en cada uno de esos países; y por otro, conocer los discursos del profesorado en activo y en formación en aspectos concernientes al mundo educativo desde el contexto iberoamericano.

\section{Currículo y las prácticas escolares en el contexto de la pandemia}

Para tratar de las políticas educacionales y las prácticas en estos tiempos de incertidumbre (Giddens, 1991), que en este artículo va denominarse como tiempos de pandemia, nos valemos de las contribuciones de Ball $(2001,2011)$ y la concepción del ciclo de políticas con el objetivo de intentar reflexionar acerca de las determinantes globales y las respuestas locales en medio de la crisis educacional, social y política impuesta por el avance del COVID-19.

El concepto de ciclo de políticas expuesto por Ball al analizar las políticas educacionales, remite al análisis de gerencialismo y accountability en las políticas públicas, además de la performactividad y de la relación entre las macro y micropolíticas. El autor afirma que una de las directrices presentes en las políticas implementadas en el Reino Unido desde 1988 es la "[...] dirección de posibilidades de financiación y responsabilidad (accountability) relacionadas con el desempeño." (Ball, 2011, p.25)

Los análisis de Ball acerca del ciclo de políticas buscan comprender las reformas educacionales en el contexto de globalización, lo que se ha convertido en un hito de sus investigaciones a partir de los años 2000. En las décadas precedentes, dicho investigador británico destacó por investigar las políticas educacionales en al ámbito de las micropolíticas, o como las políticas educacionales de implementación de un currículo único se realizaban en las escuelas de Reino Unido (Rosa, 2019). El concepto de performactividad en educación, discutido por aquel autor, ha sido igualmente y ampliamente utilizado en las investigaciones educacionales en Brasil, ya que la performactividad estaría puesta como elemento central de las políticas nacionales e internacionales de evaluación, al definir rankings y niveles de desempeño de los estudiantes en las evaluaciones, que definen una métrica teniendo en cuenta un currículo único definido por los gobiernos nacionales

Para el autor, la "imposición y el cultivo de la performactividad en la educación y en el sector púbico, sumados a la importación y difusión del gerencialismo igualmente requieren y estimulan un mayor conjunto de formas de organización y culturas institucionales" (Ball, 2011, p.25). Con ello, desempeño y cultura institucional están imbricadas, pero no son de 
ninguna manera, únicas (LOPES; CUNHA; COSTA, 2013). Por el contrario, posibilita la divulgación de diferentes modelos de cultura institucional y respuestas locales a los problemas, como performactividad.

Lo que vemos en medio de la pandemia como respuesta de los gobiernos nacionales y subnacionales a la crisis sanitaria es un buen ejemplo de eso. Ocurre lo mismo con las políticas educacionales y las respuestas escolares, profesores e instituciones frente a las condiciones sociales, económicas y sanitarias en los contextos locales.

Examinando la relación entre las ciencias políticas y el análisis de políticas públicas, Ball (2011, p.37) elige pares conceptuales de análisis. Uno de ellos es el "[...] contraste entre la concepción de política que trata las políticas como claras, abstractas y fijas en oposición a otra en que las políticas son vistas como desactualizadas, incompletas, incoherentes e inconstantes". La primera concepción remite al estudio de que las políticas son o deben ser realizadas de la misma manera en todos los lugares o análisis de políticas con un alcance global. La segunda nos remite a la consideración de que las condiciones, recursos, historias y compromisos locales serán diferentes, y la realización de políticas puede, junto con todo eso, ser diferente en cada contexto, es decir, se debe tener en consideración el contexto de micropolíticas. Para el autor, cuando se analizan las políticas educacionales como políticas públicas, ese binario debe ser considerado, pero el "abordaje de la trayectoria" capta las formas por las cuales las políticas evolucionan, se modifican y decaen a lo largo del tiempo y del espacio, así como sus incoherencias" (BALL, 2011, p.38).

Para una propuesta analítica que tiene como objetivo aprehender la dinámica global de las políticas o de las políticas educativas en particular, Ball (2011) defiende la utilización del abordaje de la trayectoria política, o ciclo de política. Este abordaje involucra la concepción de política como política en movimiento. Involucra aún su proceso de desarrollo, la producción de texto político y su puesta en práctica, insertada en el contexto de influencia, llegando incluso al campo de la práctica y sus efectos.

La trayectoria de las políticas puede desvelar en contextos y tiempos de incertidumbre una riqueza de respuestas que, al intentar sobrellevar situaciones mundialmente impuestas, llevan a la elaboración y reafirmación de políticas locales, considerando la diversidad y culturas e institucionales locales. Como será tratado en la siguiente sección, los comentarios hechos en el GEOFORO como contribución al debate acerca de los aprendizajes y experiencias de enseñanza durante la pandemia del COVID-19, es posible comprender esas distintas trayectorias. Aun siendo un "mal" global, como probablemente describiría Baudelaire, se puede identificar en los comentarios experiencias que reafirman los rasgos de las culturas escolares locales.

En este contexto, la performactividad que remite al desarrollo de prácticas de evaluación e implementación curricular, la comparación entre los rankings locales y mundiales para escuelas, estudiantes y sistemas de enseñanza, son menos importantes que encontrar estrategias para lograr la permanencia del vínculo entre escuelas y sociedad, la continuación de los estudios en diferentes niveles de enseñanza y la valoración de respuestas locales impuestas por la problemática global. "El sentido de hibridismo es incorporado por Ball en los procesos de recontextualización considerando, en conformidad con Appadurai (2001), 
que no hay culturas puras, solamente flujos disyuntivos caracterizados por movimientos constantes y divergentes de ideas, ideologías, personas, imágenes, tecnologías, eventualmente concebidos como estables por la incapacidad de nuestros dispositivos para identificar y lidiar con el movimiento" (CUNHA; COSTA, 2013, p. 395). Aquí encontramos un punto de intersección entre los análisis de Ball (2011), Goodson (2007, 2008) y Gimeno Sacristán (2000).

Gimeno Sacristán (2000) propone un modelo de interpretación de currículo como algo construido a partir de influencias y campos que son, simultáneamente, diferenciados e interrelacionados. Para ese autor, es posible identificar seis niveles o fases de objetivación del currículo: el currículo prescrito, el currículo presentado a los profesores, el currículo moldeado por los profesores, el currículo en acción, el currículo llevado a cabo como resultados de la práctica docente y el currículo evaluado. El currículo prescrito corresponde a los documentos que sirven como referencia en la ordenación del sistema curricular y es el punto de inicio para la elaboración de materiales didácticos que serán encaminados y utilizados por los profesores. Desde esa perspectiva, el currículo prescrito asume el papel significativo, no porque llegue a la escuela por medio de la acción del Estado, sino porque será referencia para un rango de acciones curriculares, de los agentes modeladores del currículo a los docentes que lo llevan a cabo y lo evalúan.

Otra dimensión del proceso curricular es aquella que se hace por medio de la actuación de distintos agentes y que es continuamente evaluado; Gimeno Sacristán (2000) lo denomina currículo moldeado por los profesores en acción, pues, en el proceso de planear la práctica y llevarlas a cabo, el profesor construye significaciones e interviene en la configuración de las propuestas curriculares. A partir de esa perspectiva, los profesores son sujetos de un proceso de enseñanza-aprendizaje, cumplen un papel de mediador entre el currículo establecido y el que se pone en práctica; no son meros objetos de los contenidos mínimos prescritos por los agentes académicos y grupos hegemónicos.

Para Goodson (2008), la relación entre conocimiento y control está en el origen de las prescripciones curriculares hechas por el Estado, desde el inicio de la historia del currículo, datada en el siglo XVI en los países europeos. Para él, el currículo depende del contexto social en donde es producido y del ambiente educacional en el cual es llevado a cabo. El currículo prescrito posee, al mismo tiempo, un significado simbólico y otro práctico, en la medida que sirve de referencia para la evaluación y el análisis público de éxitos y fracasos de la escolarización.

Existe una gran dicotomía expresa entre el currículo escrito, la teoría curricular y la práctica docente o el "[...] potencial para una estrecha relación entre la teoría y la práctica o entre el currículo escrito y el activo, depende de la naturaleza de la construcción [...] así como de su ejecución interactiva en aula de clase" (GOODSON, 2008, p.24). Presentado con otras denominaciones, es el proceso de elaboración del currículo prescrito que lo legitima y permite su aceptación junto a los profesores y será objeto de polémica y refutación. Al estudiar el currículo escrito y las condiciones políticas, históricas y sociales en que ha sido elaborado, es posible encontrar respuestas y justificaciones para las opciones hechas por los profesores en el aula de clase, esto es, en la práctica del currículo. 
El currículo escrito posee, al mismo tiempo, un significado simbólico y otro práctico, mientras sirve de referencia para la evaluación y el análisis público de éxitos y fracasos de la escolarización. Así, el autor afirma que "El currículo como prescripción sustenta místicas importantes acerca del Estado, escolarización y sociedad. Más específicamente, él sostiene la mítica de que la especialización y el control son inherentes al gobierno central, a las burocracias educacionales y a la comunidad universitaria" (GOODSON, 2007, p. 242)

Establecer estas interrelaciones y construir esas interfaces estará, sobre todo, condicionando a otras etapas del proceso curricular, que van más allá del currículo prescrito y del currículo examinado. Dependen, sobre todo, del currículo en acción (Gimeno Sacristán, 2000), del currículo como práctica (GOODSON, 2008) y del contexto escolar en el que los currículos son ejecutados (LOPES; MACEDO, 2011).

Macedo (2006, p. 288) contribuye a ese debate al afirmar que "[...] la producción de los currículos formales y la vivencia del currículo son procesos cotidianos de la producción cultural, que envuelven relaciones de poder sea en el nivel macro o micro. En ambos son negociadas diferencias. De los dos participan sujetos culturales con sus múltiples pertenencias." La autora defiende que es necesario comprender las relaciones y posibilidades de acciones como paradojas, sea en su plano formal o en la dimensión de lo vivido. Es decir, el proceso curricular capta indiferentemente documentos curriculares, prácticas escolares y los discursos producidos por las comunidades académicas que se dedican a las investigaciones y a la elaboración de documentos curriculares, cursos de formación continuada y publicaciones acerca de las investigaciones hechas. Esa correlación entre los sujetos y los discursos producidos corrobora la producción de distintos discursos y realidades, incluso en caso de que haya una convergencia de políticas en el mundo global (LOPES; MACEDO, 2011). Estamos de acuerdo con Costa (2018) cuando afirma que de nada sirve la distinción de las etapas curriculares o el debate segmentado entre el currículo como práctica y el currículo como prescripción. Es necesario intentar comprender las dimensiones curriculares que se presentan en la realización de la práctica docente, lo que implica, esencialmente, el reajuste entre las dimensiones del proceso curricular.

Reconocer, por tanto, dicha correlación entre las dimensiones curriculares y el protagonismo de los sujetos en las prácticas y vivencias cotidianas del currículo nos posibilita constituir un referencial de análisis para el debate aquí expuesto: las evidencias de los discursos y la producción de nuevos discursos escolares durante la pandemia e identificar las correlaciones entre los discursos/experiencias escolares en tres países iberoamericanos. Si el currículo como prescripción es místico, es decir, no se efectúa en la práctica, cabe la discusión acerca de qué discursos de escolarización y prácticas escolares han sido producidos durante la pandemia.

Comprendemos que cualquier cambio que se pretenda efectivo en el ámbito de la educación escolar pasa, necesariamente, por la participación de los profesores y de la proposición de nuevas prácticas escolares. En ese sentido, estamos de acuerdo con Morgado (2005, p.99) cuando afirma que, para que tales cambios ocurran, es necesario "comprender y perfeccionar las actividades docentes y construir visiones acerca del conocimiento, la teoría y la práctica bastante distintas de las que vienen permeando la enseñanza". Así, las políticas 
curriculares para su efectiva realización necesitan de la adhesión de los profesores. Asimismo, los retos planteados para las actividades educativas en tiempos de pandemia reafirman el protagonismo del profesor que está continuamente siendo llamado a innovar, sea en las actividades didáctico-pedagógicas, en las clases síncronas y asíncronas, en los procesos de evaluación del aprendizaje y otras demandas.

\section{Aspectos metodológicos}

El propósito del artículo es realizar un análisis comparativo del impacto generado por la expansión del COVID-19 en los sistemas educativos de tres países Iberoamericanos: Brasil, Colombia, y España. Dicho análisis se realiza desde una lectura crítica y comprensiva de dos cuerpos documentales: por un lado, la legislación que contiene las acciones implementadas y las orientaciones dadas por los Ministerios de Educación a las instituciones que prestan sus servicios a estudiantes en los distintos niveles de escolaridad. Por otro lado, los aportes enviados desde los tres países al debate del foro 26 del GEOFORO Iberoamericano de Educación titulado "El Coronavirus: Una experiencia de aprendizaje".

Siguiendo la perspectiva de Creswell (1994), se optó por un diseño metodológico cualitativo centrado en procesos de indagación que permiten la comprensión de problemas sociales y humanos, en los que principalmente se da cuenta de la perspectiva de los informantes y otras fuentes documentales y testimoniales. La técnica de recolección de datos utilizada fue el análisis documental, que consiste en la realización de un conjunto de operaciones que permiten desentrañar la información contenida en uno o varios documentos (Clauso, 1993; Lüdke; André, 1986).

El enfoque utilizado para estudiar los documentos fue el análisis de contenido, ya que como plantea López (2002) "el interés del análisis de contenido no reside sólo en la descripción de los contenidos, sino en lo que éstos, una vez tratados, podrían enseñarnos relativo a otras cosas." (p.175). Para López (2002), un análisis de contenido contempla descripciones, interpretaciones y reflexiones que permiten plantear nuevas ideas sobre los contenidos que se encuentran en textos, imágenes, sonidos, películas, entre otros.

En lo que concierne a la recolección de los datos, las variables analizadas en el artículo son dos: primero, las acciones implementadas y las orientaciones dadas por los Ministerios de Educación de los tres países para que las instituciones educativas hicieran el tránsito de la presencialidad a la virtualidad en medio de la pandemia $\mathrm{y}$, segundo; los siete ejes estructurantes que articulan una serie de temas acerca de la pandemia y la educación geográfica. Estos siete ejes son categorías conceptuales que permiten comprender el significado establecido a los comentarios del profesorado participante, lo que afianza la validez interpretativa de esta investigación a dos niveles (SANDÍN, 2000). A nivel macro, para englobar la totalidad de los comentarios vertidos en el foro 26; a nivel micro para concretar las categorías anteriores en los discursos de los tres países seleccionados. La formulación de estos siete ejes temáticos ha sido otorgada por investigadores externos a este artículo científico, quienes nos han proporcionado su nomenclatura: el papel de las 
instituciones de los Estados; la pandemia: definiciones, conceptos y consecuencias; Iberoamérica ante la pandemia, las respuestas en los territorios; retos para la docencia y enseñanza en Ciencias Sociales (Geografía e Historia); los retos del aprendizaje en la situación de tele-trabajo; salud pública y privatización de la sanidad; estrategias de enseñanza frente al COVID-19, propuestas didácticas.

Teniendo en cuenta las variables de análisis mencionadas anteriormente, los documentos a analizar se organizaron en dos grupos: en el primer grupo se ubicaron aquellos que usualmente hacen parte de la legislación en los que se indicaban las acciones que implementaron los Estados y las orientaciones dadas a las instituciones educativas para dar continuidad a los procesos educativos. De estos documentos se tomó información referente a la fecha de publicación, a quien estaba dirigido, el autor, los propósitos, las acciones del Estado y las directrices a seguir por las instituciones. En la siguiente tabla (Tabla 1) se sintetiza una parte de esta información para los tres países analizados:

Tabla 1.-Sintesis de la tipología de documentos legales analizados por países

\begin{tabular}{c|l|l}
\hline País & Tipos de documentos & \multicolumn{1}{c}{ Ejemplos } \\
\hline Brasil & Ley y Decretos & $\begin{array}{l}\text { Ley } \mathrm{N}^{\circ} \text { 13.979, de 6 de febrero 2020; Medida Provisoria } \mathrm{N}^{\circ} \text { 934, } \\
\text { de } 1^{\circ} \text { de abril 2020; Portaría 347, de 03 de abril 2020. }\end{array}$ \\
\hline Colombia & Circulares y Directiva & $\begin{array}{l}\text { Circulares 019, 020, 021 de marzo de 2020, Directiva 05 de } \\
\text { marzo de 2020. Medidas para el manejo de la emergencia } \\
\text { sanitaria provocada por coronavirus (COVID-19). }\end{array}$ \\
\hline España & $\begin{array}{l}\text { Reales decretos, } \\
\text { decretos y órdenes } \\
\text { ministeriales }\end{array}$ & $\begin{array}{l}\text { Real Decreto-ley 21/2020, de 9 de junio, de medidas urgentes de } \\
\text { prevención, contención y coordinación para hacer frente a la crisis } \\
\text { sanitaria ocasionada por el COVID-19 }\end{array}$ \\
\hline
\end{tabular}

Fuente: elaboración propia a partir de la información proporcionada desde los departamentos de Educación en los tres países.

En el segundo grupo de documentos se ubicaron las aportaciones (planteamientos, reflexiones, preguntas) hechas al debate del foro 26 del GEOFORO desde los tres países. Las aportaciones se organizaron de acuerdo a su pertenencia a uno de los siete ejes temáticos nombrados anteriormente. A cada comentario proporcionado por el profesorado se le ha asignado un código completo que refleja los siguientes elementos: la procedencia del país (BR: Brasil; CL: Colombia; ES: España), el orden de intervención $(01,02 \ldots)$ y un guion bajo previo a la fecha en la que se ha realizado esa aportación. Como ejemplo, el código BR06_02/04/2020 identifica a un profesor de Brasil (el sexto en orden de intervención) que ha comentado el 2 de abril de 2020 en dicho foro 26.

En la siguiente tabla (Tabla 2) se muestra la frecuencia relativa de comentarios para cada uno de esos ejes en relación a la totalidad del foro 26 y la reformulación categórica establecida para los casos de Brasil, Colombia y España. Esto es debido a que estos tres países han sido seleccionados por su mayor participación (53 comentarios en Brasil, 26 en Colombia y 44 en España), cuyos resultados específicos favorecen la modificación parcial de los ejes temáticos. Como se puede apreciar, los ejes temáticos comunes y sus 
reconfiguraciones específicas permiten abordar la totalidad de temáticas, además de centrar la discusión posterior de los datos en los elementos comunes entre los tres países.

Tabla 2.-Cuantificación de los ejes temáticos con su frecuencia relativa y reformulación categórica

\begin{tabular}{l|l}
\hline $\begin{array}{l}\text { Ejes temáticos (macro) y frecuencia total del } \\
\text { foro 26 (entre paréntesis) }\end{array}$ & $\begin{array}{l}\text { Reconfiguración de los ejes temáticos (categorías } \\
\text { para Brasil, Colombia y España). }\end{array}$ \\
\hline Papel de las instituciones de los Estados (9.8\%) & $\begin{array}{l}\text { Gestión política de la pandemia (Brasil). } \\
\text { Valoración de la gestión política en problemáticas } \\
\text { diversas (España). }\end{array}$ \\
\hline $\begin{array}{l}\text { La pandemia: definiciones, conceptos y } \\
\text { consecuencias (15.5\%) }\end{array}$ & $\begin{array}{l}\text { Consideraciones sobre la ciudadanía y los valores } \\
\text { democráticos (Colombia). }\end{array}$ \\
\hline $\begin{array}{l}\text { Iberoamérica ante la pandemia, las respuestas en } \\
\text { los territorios (19.7\%) }\end{array}$ & $\begin{array}{l}\text { No hubo aportes de los países analizados } \\
\text { Retos para la docencia y enseñanza en Ciencias }\end{array}$ \\
$\begin{array}{l}\text { Sociales (Geografía e Historia) (8.4\%) } \\
\text { Retos del aprendizaje en la situación de tele- } \\
\text { trabajo (18.3\%) }\end{array}$ & $\begin{array}{l}\text { Repensar las estrategias y finalidades de las Ciencias } \\
\text { Sociales (Colombia). }\end{array}$ \\
\hline $\begin{array}{l}\text { (Brasil). } \\
\text { Problemas estructurales de la educación on-line } \\
\text { (España). }\end{array}$ \\
\hline $\begin{array}{l}\text { Salud pública y privatización de la sanidad (4.2\%) } \\
\text { No hubo aportes de los países analizados }\end{array}$ \\
\hline $\begin{array}{l}\text { Estrategias de enseñanza frente al COVID-19, } \\
\text { propuestas didácticas (24.1\%) }\end{array}$ & $\begin{array}{l}\text { Estrategias docentes (España). } \\
\text { Potencialidades de la educación e implicaciones para } \\
\text { la ciudadanía (Colombia). }\end{array}$ \\
\hline
\end{tabular}

Fuente: elaboración propia.

Los datos fueron sistematizados siguiendo la propuesta de De la Torre y Navarro (1990) para categorizar y sistematizar información documental. Este proceso se realizó en dos etapas. En la primera se realizó una cronología, tematización y caracterización de la información contenida en los documentos tanto de las acciones emprendidas por los Estados, las orientaciones que debían seguir las instituciones, como de las aportaciones hechas por los participantes de dicho foro 26. Para el trabajo se esta primera etapa de sistematización de la información se utilizó una matriz en forma de mapeo con los datos recolectados en los tres países. Una vez diligenciada y revisada la matriz, se procedió con la etapa de análisis e interpretación; en un primer momento se analizaron los documentos de cada país, y se pasó posteriormente a un ejercicio comparativo entre los tres países.

\section{Resultados}

Una revisión a los datos estadísticos que ha recopilado la UNESCO, nos indica el nivel de afectación de la población escolar en los países de Iberoamérica. Los tres países analizados en este artículo se vieron obligados a cerrar las instituciones de educación de todos los niveles 
y a desarrollar el trabajo escolar en casa, mediante medios virtuales y dispositivos electrónicos. Los datos de la tabla 3 son muy ilustrativos del impacto que ha tenido la pandemia en el sector educativo: el $100 \%$ de la educación presencial fue suspendida dando origen a una coyuntura que planteó grandes retos, sobre todo si tenemos en cuenta que como se señaló en la introducción, parte de las familias no contaban con los recursos para que sus hijos transitaran de la educación presencial a la virtual.

Tabla 3. Población escolar afectada por la pandemia en Brasil, Colombia y España

\begin{tabular}{c|c|c|c}
\hline Estudiantes & Brasil & Colombia & España \\
\hline Mujeres & 26.579 .822 & 6.408 .824 & 3.937 .446 \\
\hline Hombres & 26.378 .527 & 6.433 .465 & 4.059 .449 \\
\hline Total & 52.958 .349 & 12.842 .289 & 7.996 .895 \\
\hline
\end{tabular}

Fuente: elaboración propia a partir de Unesco (2020)

La tabla 4 evidencia que el mayor número de estudiantes afectados son los de primaria y secundaria que, si bien en Colombia y España no difieren mucho en el número, si muestra una diferencia de 7.011.367 estudiantes entre los dos niveles en Brasil. Por razones que también pueden obedecer a las transiciones demográficas en los tres países, tanto en Colombia como en Brasil el menor número de afectados se da en la educación preescolar, mientras en el caso de España el menor número es el de la educación superior.

Tabla 4. Distribución por niveles educativos de la población escolar afectada por la pandemia en Brasil, Colombia y España.

\begin{tabular}{c|c|c|c}
\hline Niveles educativos & Brasil & Colombia & España \\
\hline Preescolar & 5.101 .935 & 1.309 .386 & 1.321 .027 \\
\hline Primaria & 16.106 .812 & 4.303 .833 & 3.042 .396 \\
\hline Secundaria & 23.118 .179 & 4.821 .029 & 3.332 .678 \\
\hline Superior & 8.571 .423 & 2.408 .041 & 300.794 \\
\hline
\end{tabular}

Fuente: elaboración propia a partir de Unesco (2020)

\section{Disposiciones legales del estado colombiano en materia educativa en el contexto de la pandemia y los relatos del profesorado en el GEOFORO Iberoamericano}

En la revisión efectuada a las disposiciones legales realizadas por el Estado colombiano en materia educativa en el marco de dicha pandemia, se determinó la publicación 
de cuatro documentos (Tabla 5) en los que se dan directrices sobre las medidas que deben tomar los establecimientos educativos de todo el país.

Tabla 5. Disposiciones escolares del Ministerio de Educación de Colombia con motivo del COVID-19.

\begin{tabular}{l|l|l}
\hline \multicolumn{1}{c|}{$\begin{array}{c}\text { Tipo de } \\
\text { documento }\end{array}$} & \multicolumn{1}{c}{ Destinatarios } & \multicolumn{1}{c}{ Asunto } \\
\hline $\begin{array}{l}\text { Circular No. } \\
\text { 019 del 14 de } \\
\text { marzo 2020 }\end{array}$ & $\begin{array}{l}\text { Gobernadores, alcaldes, } \\
\text { Secretarios de Educación de Entidades } \\
\text { Territoriales Certificadas en Educación, } \\
\text { Rectores y Directores Rurales }\end{array}$ & $\begin{array}{l}\text { Orientaciones con ocasión a la declaratoria de } \\
\text { emergencia sanitaria provocada por } \\
\text { coronavirus (COVID-19). }\end{array}$ \\
\hline $\begin{array}{l}\text { Circular No. } \\
\text { 020 del 16 de } \\
\text { marzo 2020 }\end{array}$ & $\begin{array}{l}\text { Gobernadores, alcaldes, } \\
\text { Secretarios de Educación de Entidades } \\
\text { Territoriales Certificadas en Educación, } \\
\text { Rectores y Directores Rurales }\end{array}$ & $\begin{array}{l}\text { Medidas adicionales y complementarias para el } \\
\text { manejo, control y prevención del coronavirus } \\
\text { (COVID-19). }\end{array}$ \\
\hline $\begin{array}{l}\text { Circular No. } \\
\text { 21 del 17 de } \\
\text { marzo 2020 }\end{array}$ & $\begin{array}{l}\text { Gobernadores, alcaldes, } \\
\text { Secretarios de Educación de Entidades } \\
\text { Territoriales Certificadas en Educación, } \\
\text { Rectores y Directores Rurales }\end{array}$ & $\begin{array}{l}\text { Orientaciones para el desarrollo de procesos de } \\
\text { planeación pedagógica y trabajo académico en } \\
\text { casa como medida para la prevención de la } \\
\text { propagación del coronavirus (COVID-19), así } \\
\text { como para el manejo del personal docente, } \\
\text { directivo docente y administrativo del sector } \\
\text { educación. }\end{array}$ \\
\hline $\begin{array}{l}\text { Directiva No. } \\
05 \text { del 25 de } \\
\text { marzo 2020 }\end{array}$ & $\begin{array}{l}\text { Gobernadores, alcaldes, } \\
\text { Secretarios de Educación } \\
\text { de Entidades Territoriales Certificadas } \\
\text { y Certificadas en Educación, } \\
\text { nordenadores del gasto de Fondos de } \\
\text { Servicios Educativos y Consejos } \\
\text { Directivos de } \\
\text { Instituciones Educativas. }\end{array}$ & $\begin{array}{l}\text { Orientaciones para la implementación de } \\
\text { estrategias pedagógicas de trabajo } \\
\text { académico en casa y la implementación de una } \\
\text { modalidad de complemento } \\
\text { alimentario para consumo en casa. }\end{array}$ \\
\hline
\end{tabular}

Fuente: elaboración propia a partir del MEN (2020).

Como se puede evidenciar en las fechas y en los asuntos de las disposiciones legales publicadas, éstas estuvieron determinadas por la evolución de la pandemia. En los dos primeros documentos se daban unas recomendaciones sobre la manera en que los actores escolares podían participar y las posibilidades de orientar las actividades académicas según el número de contagios que se estuvieran presentando en el contexto inmediato a la institución y a la aparición de síntomas relacionados con el virus en profesores y estudiantes. En los dos últimos documentos, declarada la cuarentena y ordenado el cierre de los establecimientos, se dan orientaciones para planear y ejecutar las actividades escolares en forma remota.

En términos generales los documentos tienen los siguientes componentes: una contextualización en la que se justifica la expedición del documento, recomendaciones y sugerencias sobre las maneras de orientar las actividades académicas, información acerca de los recursos y las plataformas educativas del Estado que pueden ser utilizadas por el 
profesorado para continuar con la orientación de los procesos de enseñanza y aprendizaje desde casa, información sobre ayudas económicas a las que pueden acceder las familias en condiciones de pobreza y vulnerabilidad social - que en Colombia son la gran mayoría-, recomendaciones de autocuidado para prevenir el contagio aplicables a todos los miembros de las comunidades educativas.

Debido a la estructura centralizada del Estado colombiano, estas normativas rigen para todo el territorio nacional, pero adicional a ellas, para ampliarlas y para viabilizar su ejecución, las autoridades educativas regionales y locales también usaron sus facultades para publicar documentos con orientaciones que las instituciones deben seguir. Atendiendo la naturaleza del artículo es de utilidad nombrar algunas disposiciones contenidas en la legislación publicada:

Como apoyo para la creación de ambientes de aprendizaje no convencionales que puedan estar al servicio de las estrategias diseñadas por parte de los establecimientos educativos, el Ministerio de Educación Nacional creó la estrategia de apoyo al aprendizaje Aprender Digital: Contenidos para todos, la cual cuenta con más de 80.000 recursos educativos de diverso tipo para enriquecer la mediación pedagógica. Así mismo, la parrilla de programación de Señal Colombia está diseñada para responder a los retos de fortalecimiento de competencias básicas y contará con una hora diaria por tv y radio de "profesor en casa", donde un maestro orientará diversos tipos de ejercicios pedagógicos para los niños, niñas, adolescentes y jóvenes, particularmente quienes no tienen acceso a internet o no tienen computador en casa. (Ministerio de Educación Nacional, 25 de marzo 2020. Directiva 5, p. 2-3)

Si bien el tono de los documentos ilustrados en los fragmentos hacen una invitación a continuar con los procesos de enseñanza y aprendizaje, éstos despertaron mucho inconformismo y críticas en algunos círculos académicos y en sindicatos de profesores, porque a su modo de ver, se desconocen y dan invisibilidad tanto la falta de recursos de muchas familias para emprender la educación remota, como las desigualdades e inequidades que históricamente ha tenido el país en materia de acceso a las telecomunicaciones y a los recursos tecnológicos necesarios para continuar con los procesos educativos en la coyuntura planteada por la pandemia.

Por otra parte, los aportes que se hicieron desde Colombia al debate del foro 26 del GEOFORO corresponden a los ejes temáticos: Estrategias de enseñanza frente al COVID19, propuestas didácticas; retos para la docencia, enseñanza de las ciencias sociales (historia y geografía) y la pandemia: Conceptos, definiciones y consecuencias. Los aportes al hilo generador sobre las estrategias genéricas de enseñanza, reformuladas mediante la categoría "Potencialidades de la educación e implicaciones para la ciudadanía" (52\%), subrayan la necesidad de repensar el sentido que tiene educar en la actualidad, las complejidades que generó el paso de la educación presencial a la educación virtual, la necesidad de reflexionar cómo la exigencias de productividad académica ha dejado de lado las relaciones de cuidado en los contextos escolares, principalmente en las universidades, y la importancia que tiene la 
alfabetización científica para las sociedades del mundo de hoy. El siguiente fragmento ilustra lo mencionado anteriormente:

Que la pandemia provocada por el Coronavirus es una gran oportunidad para que quienes de una u otra manera participamos en procesos educativos, nos cuestionemos la utilidad real de la enseñanza y del aprendizaje. Se ha hecho más que evidente la necesidad urgente que desde la escuela cuestionemos todas las expresiones de inequidad sobre todo la educativa, a la vez que aportemos en lo que podamos en la construcción de sociedades más justas y equitativas más allá de la retórica (CL01_01/04/2020).

En cuanto a los aportes al hilo enseñanza de las ciencias sociales (historia y geografía), los participantes colombianos reflexionan en torno a "Repensar las estrategias y finalidades de las Ciencias Sociales" (40\%). Esta reformulación hace mención a los nuevos significados que otorgan a la geografía, el territorio y los espacios vividos en el contexto de la pandemia, la necesidad de estrategias pedagógicas en Ciencias Sociales en la que sea evidente la articulación de los propósitos, las actividades de aprendizaje, variados instrumentos de evaluación y una formación ética que haga consciente a los estudiantes del valor de aprender y de educarse. Así se plasma en el siguiente comentario:

Mi comentario se dirige a visibilizar aquellos rincones de la realidad que no eran de interés para el conocimiento geográfico y que los giros de la geografía humana replantean y proponen otras posibilidades y formas de comprensión del mundo (Lindon, 2010). En este caso se refiere a los cambios se están produciendo en los espacios íntimos, domésticos y privados y su relación con el lenguaje que empleamos como ciudadanos que no deja de estar permeado por nuestro ser y quehacer docente. (CL03_01/04/2020)

El aporte al hilo conductor la pandemia: Conceptos, definiciones y consecuencias, se ha reformulado hacia "Consideraciones sobre la ciudadanía y los valores democráticos" (8\%), pues se hace una invitación a que el contexto de la pandemia no sea impedimento para continuar avanzando en la construcción del conocimiento, a trabajar colaborativamente, con implicaciones hacia el mantenimiento de los procesos educativos:

Un virus nos ha mostrado la fragilidad humana, nos ha dado una bofetada sobre ese ego de superioridad y poder sobre la naturaleza de la raza humana. Nos ha confinado, nos ha aislado, nos ha vuelto temerosos. Puede que sea una lección para nuestra arrogancia, pero no podemos permitir que nos arrebate la posibilidad de estudiar juntos, de darle a la educación y a la universidad el sentido de su significado. (CL019_25/05/2020) 


\section{La perspectiva del COVID-19 en España desde diversas fuentes documentales y su incidencia en la educación}

Los primeros casos de COVID-19 en España que fueron emitidos por los medios de comunicación se dieron durante el mes de febrero de 2020. A partir del 8 de marzo los casos de contagios aumentaron notablemente, especialmente en Madrid. Un día más tarde se cerraron los centros educativos en esa región (capital de España) y ante las recomendaciones de la Organización Mundial de la Salud que declaró este virus como pandemia internacional el 11 de marzo, el gobierno de España aprobó el Real Decreto 463/2020, de 14 de marzo, por el que se declara el estado de alarma para la gestión de la situación de crisis sanitaria ocasionada por el COVID-19. En ese decreto se recogen las competencias del gobierno que se concentrarían fundamentalmente en cuatro ministerios (Defensa, Interior, Transportes, Movilidad y Agenda Urbana, y Sanidad).

Durante la mayor parte del tiempo en la que se ha desarrollado el COVID-19 en España, las informaciones predominantes en los medios de comunicación han sido las procedentes del Ministerio de Sanidad. Diariamente se ofrecía un parte con el estado actual de la pandemia que era retransmitido en directo por las cadenas de televisión españolas (públicas y privadas). La ciudadanía era conocedora de esos datos y de la distribución de la pandemia por el territorio español, ya que los responsables sanitarios de las diferentes comunidades autónomas proporcionaban la información al gobierno de España a través del Sistema Nacional de Alerta Precoz y Respuesta Rápida (SIAPR).

Desde el 14 de marzo y durante los siguientes quince días se inició la primera fase de alarma, de otras cinco de similar duración que se prolongarían hasta el 22 de junio. En lo que respecta a la educación el artículo noveno de ese mismo decreto estableció la suspensión de la actividad docente con carácter presencial en todos los centros educativos (públicos, privados y concertados) en cualquiera de sus niveles (Educación Infantil, Primaria, Secundaria y enseñanzas universitarias). La docencia se ha desarrollado por medios digitales hasta la finalización del curso académico 2019-20 durante el mes de junio. Como se muestra en la tabla siguiente (Tabla 6), el gobierno de España ha ido aprobando una serie de medidas en diferentes ámbitos para regular las actividades de la población, además de recomendar el uso de recursos educativos del Instituto Nacional de Tecnologías Educativas y de Formación del Profesorado (INTEF) y el mismo Programa Educa en Digital: 
Tabla 6.-Síntesis de las medidas y documentos aprobados por el gobierno de España durante la pandemia de COVID-19

\begin{tabular}{|c|c|}
\hline $\begin{array}{c}\text { Ámbitos de } \\
\text { actuación }\end{array}$ & Documentos legislativos \\
\hline $\begin{array}{l}\text { Cuidado y } \\
\text { bienestar de } \\
\text { alumnado y } \\
\text { familias }\end{array}$ & $\begin{array}{l}\text { Real Decreto-ley 7/2020, de } 12 \text { de marzo, por el que se adoptan medidas urgentes para } \\
\text { responder al impacto económico del COVID-19. } \\
\text { Medidas de prevención, higiene y promoción de la salud frente a COVID-19 para } \\
\text { centros educativos en el curso 2020-21. }\end{array}$ \\
\hline $\begin{array}{l}\text { Calendario } \\
\text { escolar y } \\
\text { actividades } \\
\text { lectivas }\end{array}$ & $\begin{array}{l}\text { Orden SND/414/2020, de } 16 \text { de mayo, para la flexibilización de determinadas } \\
\text { restricciones de ámbito nacional establecidas tras la declaración del estado de alarma en } \\
\text { aplicación de la fase } 2 \text { del Plan para la transición hacia una nueva normalidad. } \\
\text { Real Decreto-ley } 21 / 2020 \text {, de } 9 \text { de junio, de medidas urgentes de prevención, contención } \\
\text { y coordinación para hacer frente a la crisis sanitaria ocasionada por el COVID-19. } \\
\text { Orden EFP/561/2020, de } 20 \text { de junio, por la que se publican Acuerdos de la Conferencia } \\
\text { Sectorial de Educación, para el inicio y el desarrollo del curso 2020-2021. }\end{array}$ \\
\hline $\begin{array}{l}\text { Enseñanzas y } \\
\text { evaluación }\end{array}$ & $\begin{array}{l}\text { Orden EFP/365/2020, de } 22 \text { de abril, por la que se establecen el marco y las directrices } \\
\text { de actuación para el tercer trimestre del curso } 2019-2020 \text { y el inicio del curso } 2020 \text { - } \\
2021 \text {, ante la situación de crisis ocasionada por el COVID-19. } \\
\text { Orden PCM/362/2020, de } 22 \text { de abril, por la que se modifica la Orden PCM/139/2020, } \\
\text { de } 17 \text { de febrero, por la que se determinan las características, el diseño y el contenido } \\
\text { de la evaluación de Bachillerato para el acceso a la Universidad, y las fechas máximas } \\
\text { de realización y de resolución de los procedimientos de revisión de las calificaciones } \\
\text { obtenidas en el curso 2019-2020. }\end{array}$ \\
\hline
\end{tabular}

Fuente: Ministerio de Educación y Formación Profesional del Gobierno de España (http://www.educacionyfp.gob.es/destacados/covid19.html).

Dado que la mayoría de medidas han afectado a los aspectos relacionados con la educación, conviene señalar algunos puntos del estudio realizado por la Fundación COTEC ${ }^{1}$ para la innovación (Zubillaga; Gortazar, 2020). En ese documento de treinta y ocho páginas se diagnostican algunos problemas estructurales de la educación en España, que han aflorado con el desarrollo de la docencia en línea. El concepto tripartito de brecha (brecha de acceso, de uso y escolar) delimitado por Fernández Enguita (2020) abre paso a los cinco escenarios posibles que se presentaron para ejecutar la docencia en niveles preuniversitarios. Además, se proporcionaron ejemplos de países (Corea del Sur, China, Japón, Singapur, Suecia y Egipto) para ayudar a tomar medidas en el sector educativo en España. La reacción del profesorado ha sido de cierta incertidumbre ante la dificultad del gobierno de España para tomar decisiones sobre la finalización del curso y la evaluación, así como las medidas para el próximo curso escolar, todavía en una situación poco concreta.

La valoración que se hace sobre la gestión y los efectos de COVID-19 en España debe ser variada y tan solo podemos ofrecer algunos datos con certeza. De entrada, es la primera 
ocasión en la que el sistema sanitario español ha experimentado las consecuencias de una pandemia que ha superado su capacidad de gestión. La capacidad de respuesta del Sistema Nacional de Salud no ha sido totalmente suficiente para afrontar el COVID-19, por lo que la Comisión para el Estudio y Evaluación tendrá que evaluar la eficacia futura del SIAPR (Arteaga, 2020), un aspecto que se ha tenido en cuenta en la mala puntuación que la OCDE ha otorgado a España en su gestión de la pandemia, otorgándole el último lugar en una lista de 33 países (ONU, 2020). En materia económica el gobierno de España ha ejecutado medidas para proteger a la ciudadanía y la pérdida del empleo mediante los Expedientes de Regulación Temporal del Empleo (ERTE), se ha ampliado la cobertura de financiación a la línea de avales del Instituto del Instituto de Crédito Oficial (ICO) y la aprobación de medidas fiscales para los autónomos y pequeñas y medianas empresas (pymes).

\section{Las opiniones del profesorado sobre el COVID-19 en España}

Los participantes españoles en el foro 26 del GEOFORO Iberoamericano son fundamentalmente docentes de Educación Secundaria de la provincia de Valencia, aunque hay registros de otras regiones españolas. Las opiniones analizadas reflejan la existencia de un pensamiento geográfico y crítico con los efectos que tendrá la pandemia sobre la ciudadanía, en base a una serie de aspectos como la educación, la economía y el sistema ecológico, que se han interrelacionado entre sí para mostrar un discurso sobre la situación vivida en torno a la enseñanza de las ciencias sociales.

La mayoría de intervenciones $(59 \%)$ han versado sobre las estrategias de enseñanza durante y con posterioridad al desarrollo de esta pandemia. Se ha defendido la necesidad de una educación crítica que problematice los contenidos didácticos y ayude a la comprensión y la intervención del alumnado en la vida pública. Este es uno de los objetivos de la Geografía y la Historia en el marco curricular español para la Educación Secundaria y el Bachillerato (Real Decreto $1105 / 2014)^{2}$, tal y como pone de manifiesto el siguiente docente:

Las noticias, ecos y ruidos de estos días nos impiden entender bien, discernir bien, a veces nos dejan en un mar de dudas. Es nuestra función apelar y reclamar el compromiso ético que tiene la educación con la sociedad, las personas y el mundo. Si la enseñanza tiene ese compromiso, la enseñanza de la geografía escolar tiene además un compromiso moral y formativo con la ciudadanía, con las demandas de conocimiento y con la explicación de los problemas ambientales y sociales relevantes, como esta pandemia y sus consecuencias (ES11_05/04/2020).

En segundo lugar, se han denunciado problemas estructurales (30\%) que se han visibilizado durante esta crisis y que ya eran patentes anteriormente en la educación. Se trata fundamentalmente de la existencia de una brecha digital que ahonda la desigualdad de clase del alumnado y de sus familias. Sobre este asunto no debe minusvalorarse la situación del alumnado que se ha denominado "periferias escolares", esto es, aquellos y aquellas que 
acceden a vías extraordinarias al sistema educativo español para conseguir el título de graduado escolar al finalizar la Enseñanza Secundaria Obligatoria. Esta es una realidad crítica en España por cuanto se sabe que entre el 25 y el 30\% escolarizado obtiene esa titulación por los programas de diversificación curricular (García-Rubio; Souto, 2020). Por tanto, la sensibilidad del profesorado ante la situación educativa del alumnado ha sido manifestada con cierto pesimismo ante el devenir político internacional, tal y como ha mostrado el siguiente docente: "Tengo miedo del mundo que vendrá. De que muchos gobiernos puedan aprovechar nuestro estado de miedo y vulnerabilidad para perpetuar los comportamientos más totalitaristas que ahora aplican ante las medidas de emergencia" (ES6_23/3/2020).

Como buena parte de los resultados anteriores son consecuencia de la gestión política de la pandemia (11\%), es preciso continuar con esta tercera categoría. La representación del virus en términos bélicos se ha concretado en un lenguaje que expresa una verdadera batalla para contener o vencer la pandemia. Bajo esta concepción se han registrado opiniones que han ampliado su visión hacia los cambios en los modos de vida de la población en torno a elementos como el trabajo, la movilidad y el ocio. Estos han sido los comentarios más abundantes dentro de esta categoría, y son los que más relación presentan con la geografía escolar desde una cosmovisión subjetiva del espacio. En concreto es pertinente destacar una referencia que se ha producido acerca de la movilidad encubierta en torno a los refugiados durante el período de confinamiento. Así, una profesora de Educación Secundaria ha señalado que "cabe destacar aquella movilidad que es invisible para muchas personas y que para el mundo occidental ha pasado totalmente a segundo plano: la de los refugiados que huyen de las situaciones inestables de sus países, ¿cómo se dará el acceso de estos a los demás países?" (ES27_30/04/2020). Otra parte de los comentarios se ha dirigido a las consecuencias de la pandemia en el medio ambiente, especialmente para advertir de la mejora en sus condiciones. De hecho, se han aportado datos concretos sobre la contaminación atmosférica y se han mencionado la situación de los canales de Venecia, entre otros aspectos. En definitiva, el profesorado espera que estas reflexiones deriven en un cambio de mentalidad, como recoge esta docente en su comentario:

Para terminar, siendo optimistas, esperemos que la situación presente produzca cambios de mentalidad en la ciudadanía. Se está demostrando que el ritmo de vida capitalista que llevamos no es sostenible, que tiene duros impactos en la economía, el medioambiente, la sanidad o la educación y que por tanto, hay que defender al sector público, a las buenas prácticas, y evitar alimentar a las empresas que publicitan caridad mientras mantienen a sus trabajadores en situaciones precarias (ES22_29/04/2020). 


\section{La pandemia en Brasil y las respuestas del Gobierno a las instituciones educativas}

En Brasil las primeras noticias de la COVID-19 llegaron en diciembre de 2019 con los primeros informes y alarmas de China, pero ¿cómo se iba imaginar que en poco más de dos meses estaría en todo el mundo? Los debates ponen en el centro la vida y la interdependencia entre los sistemas ambientales, el papel del Estado sobre las políticas en general y las políticas públicas relacionadas con la protección y el bienestar social. Casi nada se decía sobre las escuelas. Muchas reconfiguraciones en el orden económica e inversiones públicas debido a las necesidades de medidas de protección social fueran ejecutadas: medidas sanitarias, atendimientos médicos y ampliación de los hospitales en los centros en que la epidemia se presenta más agresiva. La perspectiva de los empleos y de paro como consecuencia de las medidas de confinamiento y las respuestas de los sistemas de salud y seguridad por el Estado eran las principales referencias en el debate. En esta perspectiva, en los meses de marzo hasta junio el país se puso en aislamiento social y cuarentena. Se produjo un feroz debate sobre las directivas del gobierno central que retrasaron las medidas de aislamiento en todo el país, mientras que los gobiernos estaduales empezaron a tomar medidas diferentes para cada unidad federada ${ }^{3}$ y región.

En medio de este debate, de las diferencias políticas y las desigualdades sociales y económicas en todo el país, la pandemia avanzaba y tomaba proporciones desastrosas. Los datos oficiales del ministerio de la salud indicaban en el inicio del mes de agosto, habría 2.733.677 casos de la enfermedad confirmados y 94.104 muertes en el país ${ }^{4}$.

Semejante a lo que se pasó en España, el Ministerio de Salud de Brasil recogió los datos de la pandemia en el territorio nacional, que luego fueron revisados desde las secretarías estaduales y municipales. La actualización diaria de los datos desde marzo hasta hoy evidencian una rápida distribución de la pandemia por el territorio brasileño, principalmente en los estados de São Paulo, Rio de Janeiro, Ceará y Amazonas, entre los meses de marzo y junio. Los demás estados del país experimentaron el crecimiento de la pandemia después de junio e infelizmente todavía se mantiene en expansión.

Las primeras medidas educativas fueran tomadas desde el gobierno central el 20 de marzo de 2020, con la suspensión de las clases en todo el país ${ }^{5}$. La tabla 7 presenta un resumen de las medidas educativas tomadas desde el gobierno central. 
Tabla 7. Síntesis de disposiciones del Gobierno Federal en Brasil y del Ministerio de Educación durante COVID-19

\begin{tabular}{l|l|l}
\hline \multicolumn{1}{c|}{$\begin{array}{c}\text { Tipo de } \\
\text { documento }\end{array}$} & \multicolumn{1}{|c}{ Destinatarios } & \multicolumn{1}{c}{ Asunto } \\
\hline $\begin{array}{l}\text { Ley } \mathrm{n}^{\circ} 13.979, \text { de } 6 \text { de } \\
\text { febrero de } 2020\end{array}$ & $\begin{array}{l}\text { Red federal pública y privada de } \\
\text { salud. Gobernadores, alcaldes, } \\
\text { población en general. }\end{array}$ & $\begin{array}{l}\text { Medidas para el enfrentamiento de la } \\
\text { emergencia de salud pública. }\end{array}$ \\
\hline $\begin{array}{l}\text { Media Provisoria } \mathrm{n}^{\circ} \\
934, \text { de } 1^{\circ} \text { de abril } \\
2020\end{array}$ & $\begin{array}{l}\text { Sistemas educativos en el país. } \\
\text { Red federal pública y privada. } \\
\text { Rectores de las universidades } \\
\text { públicas federales. }\end{array}$ & $\begin{array}{l}\text { Establece normas excepcionales para el año } \\
\text { lectivo de la educación básica y superior. } \\
\text { Reducción del calendario escolar para 75\% de } \\
\text { la carga horaria de los cursos y días lectivos } \\
\text { en todas las redes educativas en el país. }\end{array}$ \\
\hline $\begin{array}{l}\text { Portaría } \mathrm{n}^{\circ} 347, \text { de } 03 \\
\text { de abril 2020. }\end{array}$ & $\begin{array}{l}\text { Rectores de las universidades } \\
\text { públicas federales con cursos de } \\
\text { formación en salud. }\end{array}$ & $\begin{array}{l}\text { Autoriza la anticipación del diploma a los } \\
\text { estudiantes de cursos de Medicina, } \\
\text { Fisioterapia y Medicina, Enfermería, }\end{array}$ \\
& $\begin{array}{l}\text { Farmacia y Fisioterapia, que ya tengan } \\
\text { cumplido 75\% la carga horaria del curso. }\end{array}$ \\
\hline
\end{tabular}

Fuente: Ministério da Educação (MEC) [https://www.gov.br/mec/pt-br]

Importante mencionar aquí que en Brasil las medidas tomadas por el gobierno central (gobierno federal) se aplican a las redes públicas federales y los gobiernos estaduales y municipales, responsables por redes locales y de provincias, también tuvieron que dar respuestas y definir otras medidas complementarias, muchas veces distintas de las orientaciones del gobierno central. El texto de la Medida Provisoria $n^{\circ} 934$ reconoce esta autonomía de los entes federativos en su redacción y en la determinación de la reducción del calendario escolar, remite las decisiones finales a las redes específicas. En las escuelas de educación básica no es necesario cumplir un mínimo de 200 días lectivos y carga mínima de ochocientas horas, de acuerdo con las reglas editadas por los respectivos sistemas educativos. Las universidades deben cumplir con el número mínimo de jornadas lectivas obligatorias, en los términos de las normas que serán editadas por los respectivos sistemas educativos.

Existen, también, las redes educativas privadas que siguen calendarios propios y así, se dificulta la realización de un balance con fechas de cierre y pronóstico de reapertura de clases para las redes locales o de las respuestas específicas de las redes sobre los aportes tecnológicos utilizados para seguir con los estudios en las clases virtuales síncronas o asíncronas. Lo más importante para nuestra discusión y comprensión de los comentarios en el foro 26 del GEOFORO Iberoamericano que haremos en seguida es que nuestra rutina fue transformada en la escuela y las concepciones higienista necesarias en este tiempo han sido hegemónicas en los debates. Pero, más que medidas disciplinarias es necesario identificar en las respuestas los procesos formativos. Miles y miles de docentes, alumnos y sus familias discutieron sobre cuáles serían los impactos de la pandemia y las rutinas establecidas en la práctica escolar. 


\section{Los relatos del COVID-19 en Brasil: de las críticas en la gestión a las propuestas para una enseñanza renovada de la geografía escolar}

El profesorado en activo y en formación de Brasil ha sido el más participativo en el foro 26 sobre COVID-19. Además, los y las docentes han interactuado con el resto de participantes de otros países y se ha logrado la participación de profesionales ajenos al mundo de la educación, entre ellos, el comentario de un biomédico. En total, los comentarios procedentes de Brasil han ascendido a 53 y su interpretación ha permitido clasificar las respuestas en tres categorías que comentamos a continuación: la gestión política de la pandemia, los problemas acontecidos en el desarrollo de la docencia on-line y las potencialidades de la educación geográfica para explicar esta pandemia y el mundo global. Se trata de categorías excluyentes, si bien es cierto que la extensión de los comentarios ha permitido que algunos y algunas participantes abordasen temáticas que se clasifican en más de una categoría.

La mayor parte de los comentarios han versado sobre la valoración de la gestión que se ha hecho de la pandemia desde el poder político. Esta es la categoría que cuenta con un 58\% de los resultados, de cuyo análisis se desprenden varios elementos. El primero es la descoordinación entre las escalas de gobierno, especialmente entre el gobierno federal y los gobiernos estaduales. Este aspecto ha sido recurrente y se ha ejemplificado para el caso de São Paulo y otros municipios, que han presentado dificultades para tomar medidas más acordes con las necesidades de su población. Como ejemplo, el siguiente comentario expresa la falta de servicios en un municipio perteneciente a São Paulo:

Primeiramente, temos no Brasil uma grande discordância entre o governo federal e os estaduais, o que faz a população desacreditar muitas vezes sobre a letalidade do vírus, isso se deve muito ao pensamento trazido pelo atual "presidente" da República, no qual anda fazendo vários desserviços. Vamos as medidas adotadas pelo município em que resido, do qual tenho propriedade para falar. No sentido de fechamento de escolas, seguiu o estado de SP, fechando no dia 23/03, o comércio parou uma semana após isso (BR23_23/04/2020).

Una consecuencia que evidencia los comentarios ante esa gestión ineficaz de la pandemia es sobre el sistema de salud pública. El profesorado ha criticado la falta de recursos y la existencia de problemas estructurales que han aumentado desde el inicio de la pandemia, llegándose a constatar la falta de testes para prevenir sus efectos, como también ha ocurrido en otros países. Así, lo manifestó un profesora el 24 de abril, añadiendo que "É sabido que os dados a respeito dos números divulgados estão subnotificados, porque o país não dispõe de ampla testagem; os testes para detectação do coronavírus estão apenas destinados aos pacientes internados ou aos que morreram". A esto se añade la desigualdad en el acceso a la salud, llegándose a definir como una pandemia de clase, tal y como afirma el siguiente profesor: 
[...] o progresso da Covid-19 no Brasil revelou características de uma pandemia de classe. São pessoas que pode se dar ao luxo de se isolar querendo impor a força de trabalho de produção àquelas que estão com o maior risco de contrair o vírus. Assim sendo, neste contexto complexo, teríamos de ampliar este debate essencialmente para o setor público em se tratando de um sistema de saúde debilitado e preocupante, mas, infelizmente, pouco se comenta sobre o tema. (BR12_01/04/2020).

Entre los ejemplos de grupos sociales más desfavorecidos con las medidas tomadas para contener la pandemia se han criticado dos aspectos. Por un lado, las condiciones de vida de los residentes en barrios más pobres como las propias favelas. Esa población no reúne las características en infraestructuras ni salud para contener la pandemia, pese a que sea eficaz la contención. Por otro, los duros requisitos para acceder a esas ayudas económicas. Los beneficiarios de $600 \mathrm{R} \$$ (seiscientos reales brasileños) mensuales deben ejercer una actividad económica como emprendedores a título individual, entre otros elementos, lo que excluye a colectivos que ejercen actividades informales. Un ejemplo son las mujeres travestis que ejercen la prostitución ilegal antes de cumplir la mayoría de edad. Por tanto, la educación se muestra como una vía de especial relevancia para mejorar las condiciones de la población más afectada por esta pandemia, como se verá en la siguiente categoría.

El desarrollo de la educación en línea ha desencadenado una serie de problemas que ha perjudicado tanto al profesorado como al alumnado. Esta segunda categoría recoge el 36\% de los resultados proporcionados por los participantes brasileños. En un primer momento los comentarios apelan a la premura con la que se han tomado decisiones para planificar la docencia por medios telemáticos. El profesorado asume la falta de formación para enseñar con recursos tecnológicos, así como algunas deficiencias que tiene el alumnado para trabajar con dispositivos electrónicos. Como problema específico del profesorado se han registrado algunos comentarios acerca de la pérdida de intimidad de su identidad docente. Este hecho es consecuencia del desarrollo de la docencia en línea por dispositivos que ponen en cuestionamiento la integridad docente, pues se intercambian datos personales (número de teléfono) y no se respetan los tiempos de descanso del profesorado. Así lo han indicado en este comentario, que resume bien lo que acabamos de señalar:

Colocaram nós professores em grupos de whatsapp com alunos e pais de alunos, para passar atividades, (fiquei sabendo no dia 23 que deveria enviar atividades). Uma das coisas que já de início me incomodou foi tirar a privacidade do professor em ter seu número de telefone pessoal a mostra para todos (inclusive os alunos me ligaram, tive que bloquear alguns) (BR30_23/4/2020).

La tercera categoría construida a partir de los comentarios del profesorado brasileño es la que más se ajusta a los propósitos del GEOFORO Iberoamericano. A pesar que no cuenta con demasiados resultados (apenas el 6\%), sus reflexiones son de suma importancia para afrontar soluciones a la pandemia desde el ámbito de la geografía escolar. La educación 
geográfica que se reivindica parte de los postulados del geógrafo Milton Santos y se destaca una nueva forma de repensar la globalización, que conectan con las características de la pandemia. De hecho, se enfatiza el papel de la geografía como ciencia interdisciplinar que explica el origen, la distribución, la percepción y las consecuencias de dicha pandemia. Sobre estos dos aspectos se han sintetizado dos comentarios de profesores brasileños:

Vejo que em meio a pandemia a análise das espacialidades do COVID-19 através da interdisciplinaridade é de extrema importância. A Geografia contribui com o seu olhar múltiplo: político, econômico, cultural e físico. Junto às demais ciências, fortalece o estudo da origem e da globalização do vírus, além das diversas formas de combatê-lo seja a partir das orientações oficiais, seja na exigência aos governos quanto às medidas de investimento à saúde e as garantias de seguridade social, principalmente à população subalternizada. (BR37_2/5/2020).

En un plano más relacionado con la innovación escolar, se han concretado algunas prácticas docentes para abordar la enseñanza de temas relacionados directa o indirectamente con esta situación de crisis sanitaria. El profesorado ha proporcionado referencias sobre elementos de estudio como la población, los problemas de alimentación, de infraestructuras y de las medidas para el aislamiento social de los grupos más vulnerables. Además, ¡se ha hecho referencia al proyecto de innovación internacional de la red del Proyecto Nós Propomos!, pues ayuda a la formación ciudadana del alumnado en base a propuestas didácticas que trabajan un problema social o ambiental desde la escala local y de relevancia internacional.

\section{Conclusiones finales}

Una lectura reflexiva de los aportes enviados por los participantes al debate 26 del GEOFORO sobre las maneras como estudiantes, docentes y directivos han sorteado el tránsito de la educación virtual a la presencial y las maneras como se han desarrollado las clases en las múltiples modalidades que ha posibilitado la educación online, conectan con los planteamientos de Ball (2011), Goodson (2007, 2008) y Gimeno Sacristán (2000), sobre la importancia de considerar y estudiar el currículo como una construcción permanente a partir de influencias y campos que son, al mismo tiempo, diferenciados e interrelacionados. Los aportes hechos por los participantes evidencian que en el contexto de la pandemia generada por la expansión del COVID-19 tanto en la enseñanza de la geografía como en otros campos del saber, el plan de estudios depende del contexto social en el que se produce y del entorno educativo en el que se lleva a cabo. Dicho plan tiene, al mismo tiempo, un significado simbólico y un significado práctico, en la medida en que sirve como referencia para la evaluación pública y el análisis de los éxitos y fracasos de la escolarización.

Lo anterior lleva a superar la visión del currículo como documento en el que se transcriben orientaciones pedagógicas y didácticas que ocasionalmente se implementan. 
Revitaliza la idea de un currículo en acción y como práctica real y contextualizada (Gimeno Sacristán, 2000; Goodson 2008). Las aportaciones hechas al GEOFORO desde de Brasil, Colombia y España, en las que se reflexiona sobre la importancia de la flexibilidad curricular y de la importancia de prácticas pedagógicas pertinentes, en las que se diseñan e implementan estrategias desde las necesidades de los entornos y los estudiantes, revalidan los planteamientos que se hicieron en la fundamentación teórica del artículo sobre la correlación entre las dimensiones curriculares y el protagonismo de las asignaturas en las prácticas y experiencias diarias del currículo. El asunto reviste importancia porque permite constituir una referencia analítica para el debate presentado en el artículo, sobre la evidencia de los discursos y la producción de nuevos discursos escolares durante la pandemia identificando las correlaciones entre discursos/experiencias escolares en tres países iberoamericanos. Si el currículo no es real, sino que está configurado como receta mística, es decir, no se lleva a cabo en la práctica, vale la pena reflexionar sobre los discursos que se han producido en de escuela y prácticas escolares ejecutadas durante la pandemia.

Lo que han evidenciado las prácticas pedagógicas en el contexto de la pandemia según las aportaciones hechas al GEOFORO, es la importancia de superar visiones limitadas del currículo como documento que hay que seguir y centrarse en la visión que contempla el currículo como práctica (Costa, 2018). Desde esta perspectiva, es necesario comprender las dimensiones curriculares que se presentan al llevar a cabo la práctica docente, lo que necesariamente implica la reorganización entre las dimensiones del proceso curricular. También se hace necesario subrayar planteamientos como los de Morgado (2005) según los cuales la ocurrencia de cambios en las estrategias de la enseñanza - en este caso de las ciencias sociales- está determinada entre otros factores por una mejor comprensión y mejora de las actividades de enseñanza y construcción de diversos puntos de vista sobre el conocimiento, la teoría y la práctica muy diferentes de los que han permeado enseñanza; en esa medida, las políticas curriculares para su realización efectiva necesitan la adhesión y compromiso de los docentes.

Para terminar, podemos decir que la resistencia al cambio de las prácticas educativas que destacan los comentarios tiene origen en la sensación de que los cambios vienen cuando tenemos un mal desempeño profesional como docentes. Eso trae una sensación de inestabilidad y amenaza a las cuales resistimos. En el caso de una pandemia la amenaza es real y los cambios son determinados socialmente y por los gobiernos. En el ámbito educativo, en la educación formal, el cambio brusco de clases presenciales hacia actividades a distancia implicó muchos procesos de resistencia de los docentes, de las instituciones educativas y sus alumnos. En estas situaciones la vulnerabilidad y la resistencia puede generar, también, actitudes innovadoras, con clases y experiencias de enseñanza condicionadas por la percepción de los docentes de que sus identidades profesionales y prácticas contribuyen para la construcción de un nuevo proceso educativo. Este es el enfoque principal que los comentarios del GEOFORO aquí analizados nos cuentan. En medio a los desabores, inestabilidad y critica a los procesos de enseñanza a distancia, es posible compartir buenas experiencias, materiales didácticos y adaptar proyectos a esta nueva realidad. 


\section{Notas}

1. Recuperado de: https://cotec.es/media/COTEC_COVID19_EDUCACION_problemas_respuestas_escenarios.pdf. Otras publicaciones pueden ser leídas en: https://cotec.es/

2. El nombre completo es Real Decreto 1105/2014, de 26 de diciembre, por el que se establece el currículo básico de la Educación Secundaria Obligatoria y del Bachillerato.

3. Como discutimos aquí Brasil, España y Colombia, es importante esclarecer que, en Brasil, como un Estado Federado, tenemos 26 unidades federadas a que denominamos Estados, así como en México. La división administrativa de Colombia y España son distintas y por eso no es posible establecer comparaciones desde el punto de vista adminis trativo, pero para fines didácticos establecemos la comparación de las medidas tomadas por los gobiernos centrales en cada país.

4. Datos de 03 de agosto de 2020. Fuente: https://coronavirus.jhu.edu/region. Para los dados de la COVID-19 en el Estado de São Paulo, lo más afectado por la pandemia puede-se acceder a https://www.seade.gov.br/coronavirus/. Para datos de las instituciones educativas en Brasil acceder a: http://portal.mec.gov.br/coronavirus/.

5. Una mirada para las medidas de los gobiernos de Latinoamérica para las distintas dimensiones económicas políticas y educativas pueden ser vistas en los boletines de la CEPAL, disponibles en: https://www.cepal.org/es/temas/covid19?utm_source=CiviCRM\&utm_medium=email\&utm_campaign=20200804_informe_covid19_cepal-ops. Los datos específicos de las medidas educativas entán https://drive.google.com/file/d/1QBG50ZOG9fdD4QTc68OFeQWca7XXgaWs/view

\section{Referencias}

ARTEAGA, F. La gestión de pandemias como el COVID-19 en España: ¿enfoque de salud o de seguridad? Real Instituto Elcano. (13/04/2020). Recuperado de: http://www.realinstitutoelcano.org/ wps/portal/rielcano_es/contenido?WCM_GLOBAL_CONTEXT=/elcano/elcano_es/zonas_es/ari42-2020arteaga-gestion-de-pandemias-covid-19-en-espana-enfoque-de-salud-o-de-seguridad. 22 de julio de 2020.

BALL, S. J. Diretrizes Políticas Globais e Relações Políticas Locais em Educação. Currículo sem Fronteiras, v.1, n.2, p. 99-116, jul./dez. 2001. Recuperado de: http://www.curriculosemfronteiras.org/ volliss2articles/ball.pdf. 17 jun. 2020.

BALL, S. J. Sociologia das políticas educacionais e pesquisa crítico-social: uma revisão pessoal das políticas educacionais e da pesquisa em política educacional. In.: BALL, S. J.; MAINARDES, J. (Orgs.). Políticas educacionais: questões e dilemas. São Paulo: Cortez, 2011. p. 21-53.

BRASIL. Lei n. 13.979. Estabelece as medidas de controle sanitário frente à COVID 19..., Recuperado de: http://www.planalto.gov.br/ccivil_03/_ato2019-2022/2020/lei/L13979compilado.htm, en 18 jul. 2020.

BRASIL, MINISTÉRIO DA EDUCAÇÃO. Portaria No 374, de 3 de abril de 2020. Dispõe sobre a antecipação da colação de grau para os alunos dos cursos de Medicina, Enfermagem, Farmácia e Fisioterapia... Recuperado de: https://www.in.gov.br/en/web/dou/-/portaria-n-374-de-3-de-abril-de-2020-251289249, en 18 jul. 2020.

BRASIL, Medida Provisória n ${ }^{\circ}$ 934, de 02 de abril de 2020.Estabelece normas excepcionais sobre o ano letivo da educação básica e do ensino superior..., Recuperado de: https://www.in.gov.br/en/web/dou/-/medidaprovisoria-n-934-de-1-de-abril-de-2020-250710591 en 18 jul.2020.

BOLETÍN OFICIAL DEL ESTADO. Orden EFP/361/2020, de 21 de abril, por la que se adoptan medidas excepcionales en materia de flexibilización de las enseñanzas de Formación Profesional del Sistema Educativo y de las enseñanzas de Régimen Especial. Recuperado de: https://www.boe.es/boe/dias/2020/04/23/pdfs/BOE-A-2020-4575.pdf, en 22 de julio de 2020. 
BOLETÍN OFICIAL DEL ESTADO. Orden EFP/365/2020, de 22 de abril, por la que se establecen el marco y las directrices de actuación para el tercer trimestre del curso 2019-2020 y el inicio del curso 2020-2021, ante la situación de crisis ocasionada por el COVID-19. Recuperado el 22 de julio de 2020, de https://www.boe.es/boe/dias/2020/04/24/pdfs/BOE-A-2020-4609.pdf

BOLETÍN OFICIAL DEL ESTADO. Orden EFP/561/2020, de 20 de junio, por la que se publican Acuerdos de la Conferencia Sectorial de Educación, para el inicio y el desarrollo del curso 2020-2021. Recuperado el 22 de julio de 2020, de https://www.boe.es/eli/es/o/2020/06/20/efp561/com

BOLETÍN OFICIAL DEL ESTADO. Orden PCM/362/2020, de 22 de abril, por la que se modifica la Orden PCM/139/2020, de 17 de febrero, por la que se determinan las características, el diseño y el contenido de la evaluación de Bachillerato para el acceso a la Universidad, y las fechas máximas de realización y de resolución de los procedimientos de revisión de las calificaciones obtenidas en el curso 2019-2020. Recuperado el 22 de julio de 2020, de https://www.boe.es/buscar/pdf/2020/BOE-A-2020-4576consolidado.pdf

BOLETÍN OFICIAL DEL ESTADO. Orden SND/414/2020, de 16 de mayo, para la flexibilización de determinadas restricciones de ámbito nacional establecidas tras la declaración del estado de alarma en aplicación de la fase 2 del Plan para la transición hacia una nueva normalidad. Recuperado el 22 de julio de 2020, de https://www.boe.es/eli/es/o/2020/05/16/snd414/com

BOLETÍN OFICIAL DEL ESTADO. Real Decreto 1105/2014, de 26 de diciembre, por el que se establece el currículo básico de la Educación Secundaria Obligatoria y del Bachillerato. Madrid: Boletín Oficial del Estado. Recuperado el 24 de julio de 2020, de https://www.boe.es/boe/dias/2015/01/03/pdfs/BOE-A-201537.pdf

BOLETÍN OFICIAL DEL ESTADO. Real Decreto 463/2020, de 14 de marzo, por el que se declara el estado de alarma para la gestión de la situación de crisis sanitaria ocasionada por el COVID-19. Ministerio de la Presidencia, Relaciones con las Cortes y Memoria Democrática «BOE» núm. 67, de 14 de marzo de 2020 Referencia: BOE-A-2020-3692. Recuperado el 22 de julio de 2020, de https://www.boe.es/buscar/pdf/2020/BOE-A-2020-3692-consolidado.pdf

BOLETÍN OFICIAL DEL ESTADO. Real Decreto-ley 21/2020, de 9 de junio, de medidas urgentes de prevención, contención y coordinación para hacer frente a la crisis sanitaria ocasionada por el COVID-19. Recuperado el 22 de julio de 2020, de https://www.boe.es/eli/es/rdl/2020/06/09/21/com

BOLETÍN OFICIAL DEL ESTADO. Real Decreto-ley 7/2020, de 12 de marzo, por el que se adoptan medidas urgentes para responder al impacto económico del COVID-19. Recuperado el 22 de julio de 2020, de https://www.boe.es/buscar/act.php?id=BOE-A-2020-3580\#a8

CHANG, G. \& YANO, S. "How are countries addressing the Covid-19 challenges in education?" UNESCO's Section of Education Policy A snapshot of policy measures, 24. 3. 2020. Disponible en: https://gemreportunesco.wordpress.com/2020/03/24/how-are-countries-addressing-the-covid-19challenges-in-education-a-snapshot-of-policy-measures/.

CLAUSO, A. Análisis documental: el análisis formal. Revista general de Información y Documentación, 3 (2) 11-19. 1993.

COTINO, L. La enseñanza digital en serio y el derecho a la educación en tiempos de coronavirus. Revista Educación y Derecho, 21, 1-29. 2020.

CRESWELL, J. Investigación Cualitativa y Diseño Investigativo. Selección entre cinco tradiciones. $2^{\mathrm{a}}$ edición. CA, EE. UU. 2007.

DE LA TORRE, E. y NAVARRO, R. Metodología de la investigación: Bibliografía, archivística y documental. México. Editorial McGraw-Hill. 1990.

FERNÁNDEZ ENGUITA, M. Una pandemia imprevisible ha traído la brecha previsible. Cuaderno de Campo (31 marzo). Recuperado de https://blog.enguita.info/.2020, el 22 de julio de 2020. 
FITA, S., LOUREIRO, S. y SOUTO, X.M. La globalización del GEOFORO Iberoamericano en 2018. Biblio 3W, Revista Bibliográfica de Geografía y Ciencias Sociales, Vol, XXIII, n 1158 . Portal Geo Crítica. Recuperado de http://www.ub.edu/geocrit/b3w-1258.pdf. 2018, el 24 de julio de 2020.

GARCIA-RUBIO, J. y SOUTO, X.M. La invisibilidad de las periferias escolares. Diferencias personales y propuestas para mejorar el aprendizaje. Valencia: Nau Llibres. 2020.

GEOFORO IBEROAMERICANO SOBRE EDUCACIÓN, GEOGRAFÍA Y SOCIEDAD (integrado en la página web de la Universidad Nacional Autónoma de México, UNAM). http://www.GEOFORO.unam.mx/secforo/

GEOFORO IBEROAMERICANO SOBRE EDUCACIÓN, GEOGRAFÍA Y SOCIEDAD. http://GEOFORO.blogspot.com/

GIANNINI, S. \& GRANT, S. Three ways to plan for equity during the coronavirus school closures, 25.3.2020, UNESCO, (UNESCO Assistant Director-General for Education and, -UNESCO-IIEP Director). 2020. Recuperado de: https://gemreportunesco.wordpress.com/2020/03/25/three-ways-to-plan-for-equity-duringthe-coronavirus-school-closures/, en 20 jun. 2020.

GIDDENS, A. As consequências da Modernidade. 2a. ed. São Paulo: editora Unesp, 1991.

GIMENO SACRISTÁN, J. O currículo, uma reflexão sobre a prática. Porto Alegre, Artmed, 2000.

GOODSON, I. Currículo, narrativa e o futuro social. Revista Brasileira de Educação, v. 12, n. 35, maio/ago. 2007. Recuperado de: http://www.scielo.br/pdf/rbedu/v12n35/a05v1235.pdf, en 11 jun. 2020.

GOODSON, I. F. Currículo: teoria e história. 8 ed. Petrópolis: Vozes, 2008.

HARRIS, D. Using federal stimulus to get schools through the coronavirus crisis: The case for summer school and summer teacher pay. Brookings Institution, 11 de marzo. 2020. Recuperado de: https://www.brookings.edu/blog/brown-center-chalkboard/2020/03/11/using-federal-stimulus-to-getschools-through-the-coronavirus-crisis-the-case-for-summer-school-and-summer-teacher-pay/, en 12 jun. 2020.

INSTITUTO NACIONAL DE TECNOLOGÍAS EDUCATIVAS Y DE FORMACIÓN DEL PROFESORADO (INTEF). https://intef.es/

LOPES, A. C. CUNHA, E. V. R.; COSTA, H. H. C. Da recontextualização à tradução: investigando políticas de currículo. Currículo sem Fronteiras, v. 13, n. 3, p. 392-410, set./dez. 2013. Recuperado de: http://www.curriculosemfronteiras.org/vol13iss3articles/lopes-cunha-costa.pdf, en 10 jun. 2020.

LOPES, A. C; MACEDO, E. Contribuições de Stephen Ball para o estudo das políticas de currículo. In: BALL, Stephen J.; MAINARDES, Jefferson (Orgs.). Políticas educacionais: questões e dilemas. São Paulo: Cortez, 2011, p. 249-283.

LÓPEZ, F. El análisis de contenido como método de investigación. Revista de Educación, 4, 167-179. 2002.

MINISTERIO DE EDUCACIÓN NACIONAL. Circular No. 019. Orientaciones con ocasión a la declaratoria de emergencia sanitaria provocada por coronavirus (COVID-19). Recuperado de https://www.mineducacion.gov.co/1759/w3-article-393910.html?_noredirect=1 el 20 de junio de 2020.

MINISTERIO DE EDUCACIÓN NACIONAL. Circular No. 02. Medidas adicionales y complementarias para el manejo, control y prevención del coronavirus (COVID-19). Recuperado https://www.mineducacion.gov.co/1759/articles-394018_recurso_1.pdf, el 20 de junio de 2020.

MINISTERIO DE EDUCACIÓN NACIONAL. Circular No. 020. Orientaciones para el desarrollo de procesos de planeación pedagógica y trabajo académico en casa como medida para la prevención de la propagación del coronavirus (COVID-19). Recuperado de: https://www.mineducacion.gov.co/1759/w3-article394115.html?_noredirect, el 20 de junio de 2020.

MINISTERIO DE EDUCACIÓN NACIONAL. Directiva No. 05. Orientaciones para la implementación de estrategias pedagógicas de trabajo académico en casa y la implementación de una modalidad de 
complemento alimentario para consumo en casa. Recuperado el 20 de junio de 2020 de, https://www.mineducacion.gov.co/1759/w3-article-394577.html?_noredirect=1.

MINISTERIO DE EDUCACIÓN Y FORMACIÓN PROFESIONAL DEL GOBIERNO DE ESPAÑA. http://www.educacionyfp.gob.es/destacados/covid19.html

MINISTERIO DE EDUCACIÓN Y FORMACIÓN PROFESIONAL DEL GOBIERNO DE ESPAÑA (22/06/2020). Medidas de prevención, higiene y promoción de la salud frente a COVID-19 para centros educativos en el curso 2020-21. http://www.educacionyfp.gob.es/dam/jcr:7e90bfc0-502b-4f18-b206f414ea3cdb5c/medidas-centros-educativos-curso-20-21.pdf

ORGANIZACIÓN DE ESTADOS IBEROAMERICANOS (OEI). Impacto del covid-19 en la educación en Iberoamérica. Madrid: OEI. 2020.

ORGANIZACIÓN DE LAS NACIONES UNIDAS. Informe sobre los Objetivos de Desarrollo Sostenible de 2020. https://unstats.un.org/sdgs/report/2020/The-Sustainable-Development-Goals-Report-2020.pdf. 2020.

LÜDKE, M. ANDRÉ, M. Pesquisa em Educação: abordagens qualitativas. São Paulo: EPU, 1986.

PALACIOS, F. A. Programa de Educación Geográfica de la Universidad de La Serena, Chile: avances de investigación en torno al desarrollo del pensamiento geográfico. Anekumene, n. 7, 2018, p. 64-75.

PALACIOS, N. (2020) Brechas. En: Educación y Covid -19. Aproximaciones académicas de estudiantes y profesores de la Facultad de Educación de la Universidad de los Andes. Bogotá: Facultad de Educación de la Universidad de los Andes. Disponible en: https://educacion.uniandes.edu.co/images/Educacionovid/Educacion_y_Covid19_FIN.pdf

PEDRÓ, F. Covid-19 y educación superior en américa latina y el caribe: efectos, impactos y recomendaciones políticas. Análisis Carolina, 36. 2020.

PROGRAMA EDUCA EN DIGITAL DEL GOBIERNO DE ESPAÑA. Recuperado de: http://www.educacionyfp.gob.es/prensa/actualidad/2020/06/20200616-educaendigital.html. El 20 junio 2020.

ROSA, S. S. Uma introdução às ideias e às contribuições de Stephen J. Ball para o tema da implementação de políticas educacionais. Revista de Estudios Teóricos y Epistemológicos en Política Educativa, v. 4, p. 117, 2019. Recuperado de: http://www.revistas2.uepg.br/index.php/retepe, el 15 maio 2020.

RODRÍGUEZ, L.A., PALACIOS, N. y SOUTO, X.M. La construcción global de los problemas sociales desde el GEOFORO Iberoamericano. Barcelona: Geocrítica Textos Electrónicos. 2019.

SANDIN, M.P. Criterios de validez en la investigación cualitativa: de la objetividad a la solidaridad. Revisa de Investigación Educativa, 18(1), 223-242. 2000.

SHAH, S. Contra las pandemias, la ecología. Le Monde Diplomatique en español. 2020.

UNESCO. COVID-19 Educational Disruption and Response, UNESCO. 2020. Recuperado de: https://en.unesco.org/themes/education-emergencies/coronavirus-school-closures. El 15 junio de 2020.

ZUBILlAGA, A. y GORTAZAR, L. Covid-19 y educación: problemas, respuestas y escenarios. Documento técnico de análisis de la situación educativa derivada de la emergencia sanitaria. Madrid: Fundación Cotec para Innovación. Recuperado, de https://cotec.es/media/COTEC_COVID19_ EDUCACION_problemas_respuestas_escenarios.pdf., el 22 de julio de 2020 


\section{Correspondência}

Silvia Aparecida de Sousa Fernandes: É Professora na Universidade Estadual Paulista (UNESP), Faculdade de Filosofia e Ciências, Marília. Doutorado em Sociologia, mestrado em Geografia.

E-mail: sas.fernandes@unesp.br

Diego García Monteagudo: É Professor na Universidad de Valencia, Espanha.

E-mail: garmon8@uv.es

Nancy Palacios Mena: É Profesora en la Facultad de Educación - Universidad de los Andes - Colômbia.

E-mail: n.palaciosm@uniandes.edu.co

Texto publicado em Currículo sem Fronteiras com autorização dos autores 